\title{
Application of Yager's Fuzzy Logic in Sociological Research: An Instance of Potential Payoff
}

\author{
Mohammed Faruque Uddin \\ Shahjalal University of Science and Technology, Bangladesh
}

doi: 10.19044/esj.2017.v13n5p227 URL:http://dx.doi.org/10.19044/esj.2017.v13n5p227

\begin{abstract}
This article exemplifies Yager's theory of fuzzy logic for interpersonal communication to the area of social research. Taking the dilemma between qualitative and quantitative approaches into the account, there is an anticipation to make a merge between these two. There is an enormous prospect to turn up scientists' philanthropic innovations if they could use fuzzy logic in social science researches! However, by using fuzzy logic in sociological research there is a great deal of opportunity to study the social facts related to poverty, consumption, employment, intersubjectivity, social capital, environment, gender etc. How can we use Yager's theory of Fuzzy Logic to analyze the relationship between social capital and labor market partcicpation? From the experiential connection in Bangladesh society, I try to seek this answer using a hypothetical quantification of attributes.
\end{abstract}

Keywords: Fuzzy Logic, Sociology, Social Capital

\section{Introduction}

The major objective of this article is to discuss procedure of decisionmaking by using Yager's model of fuzzy logic in a sociological research. However, endless dilemma between qualitative and quantitative methods of social research is almost a paramount tension among the scholars of both non-positivist and positivist epistemologies. Taking decisions from qualitative or quantitative methods always display a grey outcome rather than in a line of binary poles (yes or no). Pearce (2012) claims that structural forces shape and are shaped by reigning methodological paradigms, or sets of widely accepted beliefs and values, even if it shifts through time. Data using in physical sciences (for example physics) deal with precise hard facts. On the contrary, social sciences always encounter imprecise soft social facts. Generally, social facts are vague and interpretative in nature. Therefore, fuzzy logic might fit the needs of social scientist looking for mathematical 
models to deal with unclear, imprecise data (Pipino and van Gigh 1981:2135). In mathematics, the fuzzy set theory was introduced by Zadeh (1965b) while in 30 years back an American philosopher Max Black (1937) also put forwarded an envision of such data and theory. Zadeh identified objects that are not precise and called it fuzzy sets. He explains that attaching membership in a fuzzy set is not affirmation or denial; rather it's a degree. Two decades later, Yager (1980) introduced another model of fuzzy set in a same manner to study interpersonal communication. In this paper, I use and apply Yager's theory for doing research in sociology.

\section{Understanding fuzzy logic for social research:}

While analyzing Qualitative Comparative Analysis (QCA), Charles Ragin (Ragin 1987, Berg-Schlosser 2001, 2003) advances macrosociological studies using fuzzy-logical operations. He included diversity of kind and of membership degree in configurational analysis. However, QCA aims to identify necessary and/or sufficient causal factors to a social outcome. Bivalent way of thinking deals with either 'yes' or 'no' started from Aristotelian logic (Kron 2005). The principle of excluded contradiction explained by Aristotle - no statement can be true and false simultaneously [ $\mathrm{x}$ $=\operatorname{not}(A \cap n o t A)]$ or the principle of excluded middle - every statements is either true or false [ $x=$ AUnotA ] initiated the fundamentals of bivalent thinking among the scientific community (Kron 2005). But, this thinking in social science research creates the 'problem of mismatching' as the social reality is grey rather than black and white (Kosko 1995). Thus, binary principle is not fully adequate to analyze social phenomena. According to Mario Bunge (1983), polar characteristics are rather exceptions and not a rule for every reality. Therefore, including polar as well as non-polar characteristics, we need alternative thinking that we can cope with diversity of social world. However, fuzzy thinking opens a new avenue to study these diversities. Kosko opines that 'fuzzy-logic is more than just a method. It implies a new worldview which focuses not just on bivalence but also on polyvalence' (Kosko 1992, 1999). Hence, the fuzzy set theory in mathematics challenges the "probabilistic monopoly" of classical Aristotelian logic over the world (Kosko 1994). Zhang describes fuzziness with unambiguous set of outcomes and the uncertainty attached in the meaning of the outcomes themselves (Zhang et.al. 1994). 


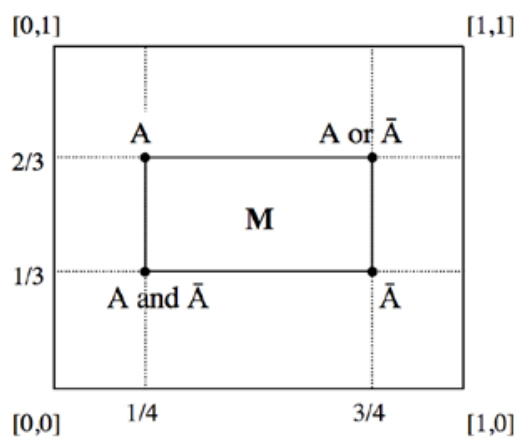

Fig 1: Fuzzy-cube (adapted from Kron, 2005:57)

A fuzzy-cube (Fig1) describes the degree of sets corresponding to their membership to certain dimensions (Kron 2005). Here, fuzzy sets represent a space in dimensions correspond to the number of elements of the basic set. These elements $[\mathrm{x}, \mathrm{y}]$ of 'fuzzy units (or 'fits') designate the degree of membership in a range of values ( 0,0 and 1,1$)$, which is calculated adding the fits. The quadrate with a side length of 1 , and a point $\mathrm{A}$ within this quadrate is a fuzzy-set A [x,y] (Kron 2005:56-59). However, one can identify the set notA, i.e. if $A[x, y]$ then notA [1-x,1-y]. Kron explains that with these two sets one can form the set union and the intersection of sets (Kron 2005:57). The latter (A-and-notA) is formed by the minimum of the membership functions, i.e $A \cap \bar{A}=\left(\min \left(x, x^{\prime}\right), \min \left(y, y^{\prime}\right)\right)$. And the set union of two sets is as $A U \bar{A}=\left(\max \left(x, x^{\prime}\right), \max \left(y, y^{\prime}\right)\right)(\operatorname{Kron} 2005: 57)$. It is then the set $\mathrm{M}$, which is the fuzziest set of all sets where the known bivalent views loose its validity. This is because sets A and notA as well as A-and-notA and Aor-notA are identical. However, we can develop a corollary that while we deal with the uncertain degree of elements of fuzzy set then the validity of bivalent nature disappears (Kron 2005:57-58).

Fuzzy analysis is a set-theoretic approach in pure mathematics. For social research, usually we use basic statistical tools like scales and indices both for cross-sectional or longitudinal study. Fuzzy set theory might generate a new thinking tool for sociological analysis. Following Ragin (Ragin 2000), I develop the example explained here. For instance, a conventional set is dichotomous: a case is either "in" or "out" of a set, for example, the set of Professors. Thus, a conventional set is comparable to a binary variable with two values, 1 ("in," i.e., Professors) and 0 ("out," i.e., not-Professors). A fuzzy set, by contrast, permits membership in the interval between 0 and 1 while retaining the two qualitative states of full membership and full non-membership. The fuzzy set of Professors could include individuals who are "fully in" the set (fuzzy membership $=1.0$, full professors), some who are "almost fully in" the set (membership $=.90$ has 
applied for professor!), some who are neither "more in" nor "more out" of the set (membership $=.5$, also known as the "crossover point", still in the middle in the stair of associate professor and professor), some who are "barely more out than in" the set (membership $=.45$, still enjoying associate professorship), and so on down to those who are "fully out" of the set (membership $=0$, out of the set of professors, merely assistant professors). It is up to the researcher to specify procedures for assigning fuzzy membership scores to cases, and these procedures must be both open and explicit so that other scholars can evaluate them. Basic sociological (phenomenological alternatives) understandings allow us to set down the notion of 'stock knowledge at hand' by which it is easy for a researcher to attach membership function in a social phenomenon.

\section{Theory and Application}

Numerous researchers already manifested their scientific endorsement about the functional entity of social capital on labor market participation where Bourdieu (1986), Coleman (1988), Putnam (2000) are the key exponents. While they are analyzing the issue they have their own background information in hand from the society. A tentative outcome scientist expects from the study while mastering the data. At least they can assume the expected relation among variables. Any social researcher can conduct researches using conventional research methods either by qualitative (FGD, Case studies, PRA etc.) or quantitative (survey, Experiment etc) with possible statistics of univariate, bi-variate, or multivariate analysis. Interestingly speaking, application of fuzzy logic might explain the research findings with possible magnitudes of alternative technique where both qualitative and quantitative data are embedded. Using a hypothetical degree of membership I explain the process focusing Yager's model of fuzzy logic.

Social capital can be seen as any social relationship, which generates utilities for individuals. Based on experiential connection in Bangladesh society, it suggests that using social capital an individual can access labor market. Eventually, (s)he can be recruited in a job. Alternatively, an individual could have no potential or effective social capital but has excellent human capital (for example grades with distinction) and using it (s)he also can access the labor market and can get a job. From these viewpoints, we cannot determine a decision that only social capital or only human capital secures the labor market participation. Because, probably there are some distortions by which the recruitment of individuals cannot be analyzed through the determinant of human capital. Excellent grades holders have chances not to be selected for jobs due to lack of social capital. On the contrary, effective social capital holders also can be rejected for lacking in human capital. It is therefore difficult to determine the precise scenario and 
inherent (invisible) facts, which really hinders functions of social capital or human capital because of both distortions from external noise (political, cultural limitations) and ambivalence on the part of its manifestation. Here is the key; conventional receiver-sender model might be useful to fit a model for analyzing the effect of social capital in labor market attainments. However, drawing a decision on people's perception about recruitment policies in a society can be measured through the Yager's theory (Yager, 1980) of fuzzy logic. I merely use scientist (sociologist) as the receiver and respondents as sender. Here, I outline the approach suggested by Yager (1980b), which models this process and the vagueness associated with it through the use of fuzzy set theory using a hypothetical data. In doing so, I use the following Yager's theory of fuzzy logic, which has been excerpted from Klir and Yuan (1995:459-463)

\section{Yager's Theory of Fuzzy Logic}

Yager developed the following theory to measure the clarity of messages from interpersonal communications. However, I explain the theory almost in the same language excerpting from (Klir and Yuan 1995:459-463)

"Suppose, $X$ constitutes the universal set of all possible signals $X$, which may be communicated by the sender. Because of the distorting factors mentioned above, a clear unique signal may not be available. Instead, the message received is a fuzzy subset $M$ of $X$, in which $M(x)$ denotes the degree of certainty of the receipt of the specific signal $x$. In order to determine whether an appropriate response can be chosen based on the message received or whether some error was involved in the communication, an assessment of the quality of the transmission must be made. Let the maximum value of membership that any $x \in X$ attains in the set $M$ correspond to the strength of the transmission. If the set $M$ has no unique maximum, then the message is called ambiguous. If the support of $M$ is large, then $M$ is considered to be general. The distance between the maximum membership grade attained in $\mathrm{M}$ and the next largest grade of any signal $\mathrm{x}_{\mathrm{i}}$ in $M$ measures the clarity of the message. When the received message is strong, unambiguous, and clear, then the signal attaining the maximum membership grade in $M$ can easily be selected as the most obvious intended communication. Difficulty occurs, however, when the message is weak, ambiguous, or unclear. In this case, the receiver must determine whether the problem in the communication lies in some environmental distortions (in which case a repetition of the signal may be requested) or in the sender of the message (in which case a response must be made that is, as far as possible, appropriate).

Usually, the receiver of the communication possesses some background information in the form of probabilities or possibilities of the signals that can 
be expected. If $P_{\left(x_{1}\right)}, P_{\left(x_{2}\right)}, P_{\left.\left(x_{3}\right) \ldots \ldots, P_{(} x_{n}\right)}$ represent the probabilities associated with each of the signals $x_{1}, X_{2}, \ldots \ldots \ldots, x_{n} \in X$, then the probability of the fuzzy event of the receipt of message $M$ is given by

$$
P(M)=\sum_{x \in X}^{n} M(x) P(x)
$$

The receiver can use this information to assess the consistency of the received message with his or her expectations. If the probability of the received message is high, then it can be assumed that little distortion was introduced by the environment. On the other hand, if the message is very clear and unambiguous, then an appropriate response can be made even if the probability of the signal was low.

Instead of the expectation or the background information being given in probabilistic form, this information may be given in the form of a possibility distribution $r$ on $X$. In this case, $r(x) \in[0,1]$ indicates the receiver's belief in the possibility of signal $x$ being sent. The total possibility of the fuzzy message is calculated as

$$
r(M)=\max _{x \in X}[\min (M(x), r(x))]
$$

As in the case of probabilistic expectation, if the received message conflicts with the expected possibility of communication, then the receiver may attempt clarification by requesting a repetition of the transmission. Before this new transmission is sent, the receiver will probably have already modified his or her expectations based on the previous message. If $r_{0}$ indicates the initial probabilistic expectations of the receiver, and $r_{1}$ is the modified expectations subsequent to the receipt of message $M$, then

$$
r_{1}(x)=\min \left[r_{0}^{\alpha}(x), M(x)\right]
$$

For each $x \in X$, where $\alpha$ indicates the degree to which past messages are considered relevant in the modification of expectations. Our procedures for signal detection now consist of the following: a test of the consistency of $M$ against the expectations and the test of the message $M_{n}$ for strength and clarity. If both of these values are high, the signal attaining the maximum value in $M$ can be comfortably assumed to be intended signal. If both tests yield low values, the expectations are modified and a repetition is requested. If only one of these tests yields a satisfactory value, then either a new signal is requested or a response is made despite the presence of doubt.

An additional complication is introduced when we consider that the receiver may also introduce distortion in the message because of inconsistency with the expectations. Let

$$
s(M, r)=\max _{x \in X}[\min (M(x), r(x))]
$$

Correspond to the consistency of the received message with the possibilistic expectations. Then let $M^{\prime}$ denote the message that receiver actually hears, where

$$
M^{\prime}(x)=M^{\mathrm{s}}(x)
$$


For each $x \in X$ where $s=s(M, r)$. The less consistent $M$ is with the expectations, the less $M^{\prime}$ resembles $M$. Since the receiver will be modifying his or her expectations based on the message thought to have been received, the new possibilistic expectation structure is given by:

$$
r_{1}(x)=\min \left[r_{0}^{1-s}(x), M^{\prime}(x)\right]
$$

for each $x \in X$.

Finally, once a determination has been made of the signal $x \in X$ that was sent, an appropriate response must be chosen. Let $Y$ be the universal set of all responses, and let $R \subseteq Y \times X$ be a fuzzy binary relation in which $R(y, x)$ indicates the degree of appropriateness of response $y$ given signal $x$. A fuzzy response set $A \in Y$ can be generated by composing the appropriateness relation $R$ with the message $M$,

$$
\begin{gathered}
A=\mathrm{R}^{\circ} M, \\
\text { or } \\
A(y)=\max _{x \in X}[\min (R(y, x), M(x))] \\
\text { for each } y \in Y .
\end{gathered}
$$

The membership grade of each possible message $y$ in fuzzy set $A$ thus corresponds to the degree to which it is an appropriate response to the message $M$. A more interesting case occurs when the elements $y \in Y$ are not actual messages, but instead indicate characteristics or attribute that the appropriate message should possess. This allows for creativity in formulating the actual response (Klir and Yuan 1995:459463)" The following example illustrates the use of this model for sociological research.

\section{Application of Yager's Theory}

In this section, I apply the above-mentioned theory in studying the relationship between social capital and labor market participation using a hypothetical data. Suppose we have the background information on the relation between social capital and labor market participation i.e. social capital might be a complimentarity to human capital of individual, which can help him/her to be recruited in the labor market. In order to analyze this relation using fuzzy logic, we need to develop a universal set of possible responses $\left(\mathrm{y}_{1}, \mathrm{y}_{2} \ldots \ldots . \mathrm{y}_{\mathrm{n}}\right)$. To determine the magnitude of the elements of response set researcher needs to attach membership to the signal set $\left(\mathrm{x}_{1}\right.$, $\mathrm{x}_{2} \ldots \ldots \mathrm{x}_{\mathrm{n}}$ ) which lies between [0,1]. For establishing membership of the elements of the response set researcher needs to generate a matrix between response set (Y) and signal set $(\mathrm{X})$ where we know response set is a universal set. We can develop these signal and response sets as figured out in the following table. 


\begin{tabular}{|c|c|c|c|}
\hline \multicolumn{2}{|c|}{ X } & \multicolumn{2}{c|}{ Y } \\
\hline $\mathrm{x}_{1}$ & Strongly Agree & $\mathrm{y}_{1}$ & people need to have only human capital \\
\hline $\mathrm{x}_{2}$ & Strongly Disagree & $\mathrm{y}_{2}$ & people need not to have only human capital \\
\hline $\mathrm{x}_{3}$ & Fairly True & $\mathrm{y}_{3}$ & people need to have political network \\
\hline $\mathrm{x}_{4}$ & Fairly False & $\mathrm{y}_{4}$ & $\begin{array}{c}\text { people need to have family or kinship } \\
\text { network }\end{array}$ \\
\hline $\mathrm{x}_{5}$ & No Comment & $\mathrm{y}_{5}$ & people need to have friendship network \\
\hline $\mathrm{x}_{6}$ & Need to alter recruitment policy & $\mathrm{y}_{6}$ & people need to have religious network \\
\hline & & $\mathrm{y}_{7}$ & people need to have civic network \\
\hline
\end{tabular}

Table 1: Elements of fuzzy sets (author's compilation drawing on Yager (1980)

By using Yager's model, now we can calculate the magnitude of the elements of response set by following procedure:-

Arbitrarily speaking researcher wants to take a decision for the following question from the respondent, which can be identified as the message from Yager's viewpoint. Suppose, the message is 'beyond human capital people need to have social capital for being recruited into the labor market in Bangladesh-how do you go with this statement?' It is expected that the respondents rank their answers (or researcher can derive scores from qualitative interviews) from the $\mathrm{X}$ set mentioned in the above table-1.

However, we assume that researcher's expectation of possible outcome for each element of signal set with following membership by the possibility distribution as ${ }^{13}$ -

$$
\mathrm{r}_{0}=(0.9,0.1,0.7,0.3,0.1,0.6)
$$

This distribution asserts that the researcher expects a large positive outcome ( 0.9 out of 1$)$ of strongly agree from respondents. The logic is 'if strongly agree scores 1 then the strongly disagree will score 0.' Suppose, from the first instance researcher received following scores for $M_{1}$ from respondents -

$M_{1}=0.1 / \mathrm{x}_{1}+0.8 / \mathrm{x}_{2}+0.4 / \mathrm{x}_{3}+0.0 / \mathrm{x}_{4}+0.1 / \mathrm{x}_{5}+0.0 / \mathrm{x}_{6} \sim 0.1 / \mathrm{x}_{1}+0.8 / \mathrm{x}_{2}+0.4 / \mathrm{x}_{3}$ $+0.1 / x_{5}$

This message shows a clear dominance of strong disagreement, which is rather inconsistent with researcher's expectation with his background information at hand. Here, using the equation 1.4, we measure inconsistency as

$$
\mathrm{s}\left(M, \mathrm{r}_{0}\right)=\max [0.1,0.1,0.4,0.1]=0.4
$$

Equation 1.5 clarifies the information again inducing some distortions in order to process the data toward decision-making. As the message is contrary to the researcher's expectations, hence the researcher introduces some distortions, as specified by (1.5) and got the following scores -

\footnotetext{
${ }^{13}$ For the purity of Yager's theory, I have used the same numbers used in Klir and Yuan (1995:459-463).
} 
$M_{1}{ }^{\prime}=0.4 / \mathrm{x}_{1}+0.9 / \mathrm{x}_{2}+0.7 / \mathrm{x}_{3}+0.0 / \mathrm{x}_{4}+0.4 / \mathrm{x}_{5}+0.0 / \mathrm{x}_{6} \sim 0.4 / \mathrm{x}_{1}+0.9 / \mathrm{x}_{2}+$ $0.7 / \mathrm{x}_{3}+0.4 / \mathrm{x}_{5}$

Based on this message from respondents researcher modifies his expectations according to (1.6) such that

$\mathrm{r}_{1}(x)=\min \left[\mathrm{r}_{0}{ }^{0.6}(x), M_{1}^{\prime}(x)\right]$

for each $x \in X$

$\mathrm{r}_{1}=0.4 / \mathrm{x}_{1}+0.25 / \mathrm{x}_{2}+0.7 / \mathrm{x}_{3}+0.0 / \mathrm{x}_{4}+0.25 / \mathrm{x}_{5}+0.0 / \mathrm{x}_{6} \sim 0.4 / \mathrm{x}_{1}+0.25 / \mathrm{x}_{2}+$ $0.7 / \mathrm{x}_{3}+0.25 / \mathrm{x}_{5}$

The researcher has thus greatly diminished his expectation of output strongly agree, somewhat increased his expectation of the strongly disagree and need to alter recruitment policy and has given up all hopes of the possibility of no comment. Suppose now, researcher wants to check and clarify the output (real fact) from respondents again for his precision development and got the following output $M_{2}$ -

$M_{2}=0.9 / \mathrm{x}_{2}+0.4 / \mathrm{x}_{5}$

The previous step is very important for reliability of data. However, this message is stronger, clearer, and less general than first answers. Its consistency with researcher's new expectation is

$$
s\left(M_{2}, r_{1}\right)=0.25
$$

Thus the message is highly contrary even to the revised expectations of the researcher, so let us suppose researcher distorts the message such that

$$
M_{2}{ }^{\prime}=0.97 / \mathrm{x}_{2}+0.8 / \mathrm{x}_{5}
$$

Researcher has thus take decision after clarification of the message he received from the respondents and led him to exaggerate the degree to which he believes that respondents have responded with need to alter recruitment policy. Let us suppose that decision the researcher makes will have characteristics from the following set $Y$ of table-1 (Klir and Yuan 1995:459463). However, let the fuzzy relation $R \subseteq Y \times X$ represent the degree to which researcher plans to respond to a given signal $x$ with the response having the attributes $y$. The following matrix gives this relation -

$$
\left(\begin{array}{llllll}
0.9 & 0.0 & 0.2 & 0.0 & 0.0 & 1.0 \\
0.0 & 0.9 & 0.1 & 0.2 & 1.0 & 0.0 \\
0.1 & 0.9 & 0.2 & 0.9 & 1.0 & 0.3 \\
0.0 & 0.5 & 0.0 & 0.6 & 0.7 & 0.0 \\
0.1 & 0.0 & 0.9 & 0.0 & 0.0 & 0.5 \\
0.0 & 0.3 & 0.2 & 0.3 & 0.4 & 0.0 \\
0.9 & 0.0 & 0.9 & 0.3 & 0.0 & 1.0
\end{array}\right)
$$

Using (1.7) we calculate the magnitude the researcher will make to the message $M_{2}$ ': $0.0 / y_{7}$

$$
A=\mathrm{R}{ }^{\circ} M_{2}^{\prime}=0.0 / \mathrm{y}_{1}+0.9 / \mathrm{y}_{2}+0.9 / \mathrm{y}_{3}+0.7 / \mathrm{y}_{4}+0.0 / \mathrm{y}_{5}+0.4 / \mathrm{y}_{6}+
$$

$$
=0.9 / \mathrm{y}_{2}+0.9 / \mathrm{y}_{3}+0.7 / \mathrm{y}_{4}+0.4 / \mathrm{y}_{6}
$$


Now the researcher can analyze the findings as, 'respondents are not convinced that only by human capital people can be recruited in the labor market. Rather they need to have a great deal of political network, a large degree of family and kinship network, and some religious network as well'.

\section{Conclusion}

Adoption and application of Yager's theory certainly has sharp contribution to analyze social data. We find that out of the vagueness of social reality, we can clarify our message and can reach at a decision. From the hypothetical data analysis we can find that individuals emphasize that beyond human capital, people need to have political, familial and religious relationships to access labor market. However, use of this logic in sociology might accelerate a huge potential payoff for both small scale and large-scale research projects. This is an all-inclusive technique of data analysis where surveys, data processing, construct validity, internal and external reliability is well designed. Most importantly in Bangladesh there is no strong domain of database for social science researchers. So installation of fuzzy logic in social science research could open auspicious avenues for social scientists mainly to demonstrate and uncover the realm of different development issues.

\section{References:}

1. Berg-Schlosser, D. (2003) "Makro-Qualitative vergleichende Methoden.” in Berg-Schlosser, D., Müller-Rommel, F. (eds.): Vergleichende Politikwissenschaft. Opladen: UTB 103-125[English Version, translated].

2. Berg-Schlosser, D. (2001) "Comparative Studies - Method and Design.” In Smelser, N. J., Paul B. B. (eds.): International Encyclopedia of the Social and Behavioral Sciences. Oxford: Pergamon, 2427-2433.

3. Black, M. (1937) "Vagueness: an exercise in logical analysis." Philosophy of Science, 4(4):427-455. (Reprinted in International Journal of General Systems. 1990. 17(2-3):107-128.

4. Bourdieu, P. (1986) The forms of capital. In Westport, J. (Ed.) Handbook of Theory and Research for the Sociology of Education. New York, NY: Greenwood, pp. 214-258.

5. Bunge, M. (1983) Epistemologie: Aktuelle Fragen der Wissenschaftstheorie. Mannheim, Wien, Zürich: Bibliographisches Institut [English Translation].

6. Coleman J S (1988) 'Social Capital in the Creation of Human Capital’, American Journal of Sociology, vol. 94. pp. S95-120. 
7. Klir, G.J and Yuan, B. (1995) FUZZY SETS AND FUZZY LOGIC: Theory and Application, Prentice Hall of India, New Delhi.

8. Kosko, B. 1994. "The Probability Monopoly.” IEEE Transactions on Fuzzy Systems. 2(1):32-33.

9. Kosko, B. 1999. The Fuzzy Future: From Society and Science to Heaven in a Chip. München, Zürich: Crown.

10. Kosko, Bart. 1992. Neural Networks and Fuzzy Systems. A Dynamical Approach to Machine Intelligence. Englewood Cliffs: Prentice-Hall.

11. Kron, T. 2005. Fuzzy-Logik für die Soziologie. In: Österreichische Zeitschrift für Soziologie 30 (2005), 3, pp. 51-88. (English Translation)

12. Pearce, Lisa D. .2012. "Mixed Methods Inquiry in Sociology." American Behavioral Scientist 56(6) 829-848.

13. Pipino, L. L. and van Gigh, J. P. 1981. "Potential Impact of Fuzzy Sets on the Social Sciences." Cybernetics and Systems 12: 21-35.

14. Putnam, R. D. 2000, Bowling alone: the collapse and revival of American community, Simon \& Schuster, New York

15. Ragin, C. C. 1987. The Comparative Method. Moving Beyond Qualitative and Quantitative Strategies. Berkeley, Los Angeles: University of California Press.

16. Ragin, C. C. 2000. Fuzzy-Set Social Sciences. Chicago, London: University of Chicago Press.

17. Yager, R. R. 1980. "On modeling Interpersonal Communication.” in Wang, P. P. and S. K.Chang, (eds.) Fuzzy Sets: Theory and Applications to policy analysis and Information Systems. Plenum Press, New York 309-320.

18. Zadeh, L. A. 1965b. "Fuzzy Sets." Information and Control, 8(3):338-353.

19. Zhang, J. Brody, C. J. and Wright, J. D. 1994. "Sociological Applications of Fuzzy Classification Analysis." Applied Behavioral Science Review 2:171-186. 